\title{
¿Son las emociones un motor de acción política? Las inundaciones en el Valle de Chalco como conflictos socioambientales
}

\author{
São as emoções um motor da ação política? Inundações no Vale de Chalco como \\ conflitos socioambientais
Are the emotions an engine of political action? Flooding in the Valley of Chalco as socio- environmental conflicts

Les émotions sont-elles un moteur de l'action politique? Les inondations dans la Vallée de Chalco en étant des conflits socio-environnementaux

\author{
Felipe de Alba* \\ (dealbamf@gmail.com) \\ Juana Martín** \\ (jmc_special@hotmail.com) \\ Alexia Macario** \\ (jalexiamacario@gmail.com)
}

Recebido em 28/12/2014, revisado e aprovado em 18/07/2015; aceito em 23/09/2015

DOI: http://dx.doi.org/10.20435/1518-70122016109

\begin{abstract}
Resumen: En el presente texto se discute sobre el miedo frente al desastre, alrededor de lo ocurrido en varias inundaciones en Valle de Chalco, municipio de la metrópolis de México. A partir de una postura socio-antropológica en este artículo se busca estudiar los conflictos socioambientales como un mélange de intersubjetividades para encontrar un tipo de acción política potencial y emergente. A través de una reflexión sobre el miedo líquido (BAUMAN, 2006) y sobre una perspectiva de análisis de conflictos llamada la comunidad hídrica imaginada (DE ALBA; SALAZAR; MARTIN, 2015) se intenta contribuir a un debate actual sobre los fenómenos hídricos de las metrópolis contemporáneas
\end{abstract}

Palabras clave: Miedo. Inundaciones. Chalco.

Resumo: Neste texto vamos discutir sobre o medo diante do desastre, sobre o que aconteceu em várias inundações no Valle de Chalco, município da metrópole do México. De uma posição sócio-antropológico neste artigo é estudar o conflito ambiental como um mélange de intersubjetividades para encontrar um tipo de potencial de ação e política emergente. Através da reflexão sobre o medo líquida (BAUMAN, 2006) e em uma perspectiva de análise do conflito chamado de comunidade imaginada água (DE ALBA; SALAZAR; MARTIN, 2015) tenta contribuir para o debate atual sobre os fenómenos de água da metrópole contemporânea Palavras-chave: Medo. Inundações. Chalco.

Abstract: In this text we discuss about fear facing disaster, around what happened in several floods in Valle de Chalco, municipality of the metropolis of Mexico. From a socio-anthropological posture in this article we aim to study the environmental conflict as a mélange of intersubjectivities to find a type of potential and emerging political action. Through the reflection on the liquid fear (BAUMAN, 2006) and on a perspective of conflict analysis called the imagined water community (DE ALBA; SALAZAR; MARTIN, 2015) attempts to contribute to the current debate on water phenomena of contemporary metropolis

Key words: Fear. Floodings. Chalco.

Résumé: Dans ce texte, nous discutons de la peur face à la catastrophe, ce qui est arrivé dans plusieurs inondations dans la vallée de Chalco, municipalité de la métropole du Mexique. D'une position socioanthropologique dans cet article est d'étudier le conflit de l'environnement comme un mélange de intersubjectivités de trouver un type de potentiel d'action et de la politique émergente. Grâce à la réflexion sur la peur liquide (BAUMAN, 2006) et sur une perspective d'analyse des conflits appelé la communauté de l'eau imaginé (DE ALBA; SALAZAR; MARTIN, 2015) tente de contribuer au débat en cours sur les phénomènes d'eau de métropole contemporaine

Mot clés: Peur. Inondations. Chalco, Mexico.

\section{INTRODUCCIÓN}

La vida contemporánea no existe sin el aditamento del riesgo: riesgo es decidir, riesgo es (no) moverse, riesgo es continuar, riesgo es existir, riesgo es respirar. El punzante concepto de
Liquid fear (miedo líquido) de Bauman (2006), refiere algo novedoso en el tratamiento de la realidad: todo proceso social, toda relación de poder implica un 'estar en movimiento'; la realidad no puede verse desde un solo ángulo, un solo tiempo o un solo lugar.

\footnotetext{
* Centro de Estudios Sociales y de Opinión Pública de la Cámara de Diputados (CESOP), Mexico city, Mexico..

** Universidad Autónoma Metropolitana (UAM), unidad Cuajimalpa, Mexico city, Mexico.
} 
Para Bauman la realidad tiene una multiplicidad de rostros, y el más fuerte, el más presente en la vida cotidiana es el miedo. Para el autor, el 'miedo líquido' refiere una época de incertidumbre, una característica también de su concepto de 'modernidad líquida' (BAUMAN, 2006). Evidencia también la ignorancia sobre la amenaza de destrucción ecológica que se cierne sobre nuestras sociedades, así como la incapacidad para determinar qué podemos hacer (y qué no) para contrarrestarla.

En el siglo XX, la ciudad vivió la urbanización como un proceso vertiginoso de "colonización" del territorio, en menoscabo de sus ecosistemas. A partir de los grandes procesos de desecamiento, los ciclos naturales fueron rotos por el hombre. Por un lado, el acelerado agotamiento de los recursos naturales, particularmente por la sobreexplotación de los mantos acuíferos y; por otro lado, un proceso de evacuación de desechos "fuera" del Valle de México, que a su paso, causa desastres frecuentes.

Para estudiar todo ello se utiliza aquí los conceptos de desastre y del miedo, como combinación de procesos donde las 'emociones articuladoras' construyen acción política.

En algunos estudios académicos se destacan principalmente dos perspectivas, particularmente sobre el análisis del concepto de desastre. La primera, se enfoca en el cuestionamiento de las acciones humanas sobre el ambiente, efectos, consecuencias y futuros. Es decir, se discute sobre la construcción social de la vulnerabilidad, que junto a las 'amenazas naturales' hacen evidentes escenarios de riesgo (ZILBERT, 2001). La segunda, se centra en las percepciones sociales o culturales del desastre, en cómo los actores involucrados definen su situación en el riesgo y el desastre. Pero también hay creencias y discursos alrededor de ello.

En este artículo se formula una perspectiva de análisis sobre el desastre como un evento 'socioambiental', que implique una vinculación entre los procesos de transformación de la naturaleza y sus consecuencias inmediatas (o no) en la población. En esta perspectiva, las emociones son un andamiaje que albergan distintas "socio-naturalezas", porque son simultáneamente realidades sociales/culturales y físicas/naturales (SWYNGEDOUW, 2011).
Desde esta perspectiva, el desastre es aquí una "vivencia socioemocional" que integra a una serie de emociones, evocando diferentes temporalidades desterritorializadas: un pasado con tradiciones cercanas a la naturaleza y un presente que quiere ser integrado a la modernidad urbana, y todo lo que representa ${ }^{1}$.

Los desastres por inundaciones son resultados de múltiples factores. Igualmente que en otros casos, las opiniones son variadas ${ }^{2}$. Existen aquellos que resaltan la importancia de desarrollar análisis complementarios, es decir, apuntan hacia la necesidad de una reflexión sobre la incertidumbre contemporánea. Aquí nos enfocaremos en tres casos de inundaciones ocurridas en Valle de Chalco (2000, 2010 y 2011), municipio ubicado en el oriente de la metrópolis de México.

Esta reflexión está articulada alrededor de tres preguntas: ¿El miedo es un factor en el poblamiento o es la segregación socioespacial lo que funcionaliza el desastre? ¿Cuáles son las formas del miedo en un escenario de desastre? ¿El miedo es motor de la acción política?

\footnotetext{
${ }^{1}$ Algunos autores abundan sobre el conflicto hídrico como el fenómeno que "desborda" las nociones territorializadas (como territorio fijo) de jurisdicción, de competencia institucional, y de adscripción política. El conflicto genera a su vez la "pertenencia" a una comunidad originaria dado que resignifica la naturaleza, lo que "motiva, genera, produce (o inhibe) la acción política bajo diversos parámetros" (DE ALBA; SALAZAR; MARTIN, 2015).

${ }^{2}$ Esto era evidente desde los estudios pioneros sobre las causas de los hundimientos en el territorio de la ciudad de México, en los inicios del siglo XX. Destaca el caso de Roberto Gayol, quien en 1925 afirmaba que la ciudad se estaba hundiendo y que la causa probable de ese fenómeno era el drenaje, lo que aparentemente era producido por las obras que él mismo había diseñado y construido. José A. Cuevas admite la conclusión de Gayol y propone otro ingeniero de nombre Nabor Carrillo, que analizara la influencia de la extracción de agua subterránea sobre el hundimiento de la Ciudad. Este último establece que la pérdida de presión en los acuíferos del subsuelo por el bombeo, provoca cambios e induce un proceso de consolidación, causa de los asentamientos a que se refería Gayol (Conferencia de Marsal en México, 1992, citada en MAZARY; PLATAS, 1999).
} 


\section{CONSTRUCCIÓN HISTÓRICA DE UNA EMOCIÓN SOCIOAMBIENTAL}

La metrópolis de México ${ }^{3}$ se localiza en una cuenca cerrada de origen volcánico y en la planicie aluvial que dejaron los antiguos lagos de Texcoco, Chalco y Xochimilco en el interior de la Cuenca del Valle de México, lo que ha originado que los fenómenos meteorológicos se conviertan en peligros naturales para la población. En dicho sentido, aunque las inundaciones son consideradas como $f e-$ nómenos naturales, en el momento de afectar a determinada población adquieren la característica de riesgo y desastre (GÓMEZ, 2004). No obstante, las inundaciones se asocian con muchos otros fenómenos socionaturales ${ }^{4}$.

Con la urbanización a lo largo de todo el siglo $X X$, los hundimientos se deben a tres factores: 1) la sobreexplotación de agua subterránea para abastecer a la población; 2) la compactación de las arcillas debido a su poca consistencia y; 3) el peso de las construcciones, regulares o irregulares que consolida aún más las arcillas ${ }^{5}$. Varias investigaciones señalan que el centro de la planicie de Chalco se hunde $40 \mathrm{~cm} /$ año donde el espesor de los sedimentos lacustres es de 300m (ORTIZ; ORTEGA, 2007) lo que produce que el nivel de las casas esté por debajo de los canales de desagüe, como el caso particular de las que se encuentran al lado del Canal de la Compañía

\footnotetext{
${ }^{3}$ También conocida como Zona Metropolitana del Valle México (ZMVM) se constituye por 16 delegaciones del Distrito Federal, 59 municipios del Estado de México y un municipio de Hidalgo. Con poco más de 20 millones de personas, que equivale a $17.9 \%$ de los habitantes del país (SEMARNAT, 2012).

${ }^{4}$ Para que un fenómeno sea considerado o no de riesgo, dependerá del lugar en donde se manifieste y que ese lugar esté ocupado o no por una comunidad vulnerable al mismo. De esta forma, si se considera o no amenaza, ello va a depender del grado de probabilidad de ocurrencia, sobre todo del nivel de afectación que dicho suceso tenga sobre esa comunidad determinada. En otros terminos, el hecho que se convierta o no en desastre dependerá de la magnitud real con que efectivamente se manifieste el fenómeno y del nivel de vulnerabilidad de la comunidad misma (WILCHES, 1993).

${ }^{5}$ De acuerdo con Marsal y Mazari (1962) cuando las arcillas blandas lacustres pierden agua y comienzan a compactarse se producen hundimientos. Ello es generalizado en la ciudad de México, con hundimientos de entre 4 hasta 8 metros de profundidad anualmente (FIGUEROA, 2007, p. 91).
}

(MAGALLANES et al., 2010; TOSCANA, $2014)^{6}$.

Chalco es la zona más baja del relieve, en donde confluyen de manera natural las corrientes fluviales que escurren por la vertiente de la Sierra de Río Frío. La mancha urbana -que cubre de pavimento el territorioaltera el balance hídrico, ya que no permite la infiltración del agua sino que hace que se escurra, lo que incrementa el riesgo de inundaciones o anegaciones (FIGUEROA, 2007, p. 88). Entonces, el desastre no es el resultado exclusivo de agentes externos (e incontrolables) por el hombre (tal como lo serían las fuerzas sobrenaturales como Dios o el destino), ni de fuerzas naturales (como lluvias, ciclones, sequías, etc.). Es el producto de la correlación entre fenómenos naturales peligrosos (como un terremoto, un huracán, un maremoto, etc.) y de fenómenos sociales.

Kenneth Hewitt (1996) concluía que "los desastres aparecieron como causados por fuerzas externas o aberraciones dentro del orden social" (HEWITT, 1996, p. 12). Por ello, el autor plantea el reto de además de ser testigos oculares es preciso considerar los sufrimientos y las historias personales de los afectados. Hewitt lo llama "caminar en el terreno".

Las personas "comunes" son rara-
mente simples pasivas y patéticas
víctimas de los desastres, a menos
que estén imposibilitadas por ellos.
Muchos sobrevivientes actúan con
coraje llevando a cabo algunas, si
no la mayoría, de las respuestas
más inmediatas de salvamento, y
las acciones humanitarias de más
largo plazo en sus propios hogares y
centros comunitarios. Las sociedades

${ }^{6}$ El Canal de la Compañía se construyó en 1994, con una extensión inicial de $6.5 \mathrm{~km}$, como parte del sistema de desalojo de aguas negras y pluviales del área metropolitana de la ciudad de México. Sin embargo, esta función ha estado obstaculizada por una serie de razones: las condiciones físiconaturales y la extracción de agua subterránea favorecen los hundimientos del suelo y cada vez que logra desbordarse provoca las inundaciones. La negligencia de las autoridades federales, estatales y municipales para su mantenimiento adecuado y, ocasionalmente, las inclemencias meteorológicas han dado como resultado la ruptura del canal en tres ocasiones (2000, 2010, 2011), causando pérdidas tangibles e intangibles, especialmente entre la población más vulnerable y más próxima al canal (TOSCANA, 2014). 
clasificadas como "tradicionales", no menos que algunas que son "modernas", prueban haber desarrollado anteriormente robustas y humanas formas de protegerse contra sequías o inundaciones. Estas acciones son frecuentemente la base más efectiva para prepararse contra futuras crisis. (HEWITT, 1996, p. 17).

\subsection{Las razones 'del quedarse'}

E Chalco, el sentimiento de apego a la tierra ha sido la representación de décadas de esfuerzo por 'hacerse' de un patrimonio, porque "conocieron de cerca las dificultades que pasaron sus padres y abuelos durante la Revolución para obtener una propiedad rústica" (BLÁSQUEZ, 2012, p. 172). La tierra entonces es un legado familiar. Después los pobladores 'no pueden irse' por miedo a que ocurra 'lo peor' o porque tienen miedo frente a la incertidumbre que dicha idea les genera. Se trata de dos problemas articulados: por una parte, un territorio precario donde se asienta una población 'sin destino'; y, por otra parte, una 'permisividad' del gobierno a las inmobiliarias para la construcción de nuevas viviendas con bajo presupuesto. En Valle de Chalco quedó la impresión que la irregularidad era ' planeada', si se consideran las inconsistencias que provocó los usos irregulares del suelo.

Lo que resulta relevante de la intervención gubernamental errática es que habría acentuado la "permisividad" de actores institucionales locales en términos de un discurso de 'desarrollo' local. En particular, destaca el Pronasol, el más importante programa social del presidente Carlos Salinas (1988-1994) y que buscaba dar impulso a la participación comunitaria ayudando a miles de personas a elevar su nivel de vida, otorgándoles los servicios indispensables y la impresión de una urbanización 'de fachada' para fines electorales (ORTIZ, 2007).

En Valle de Chalco se trataba de 'formalizar lo informal' (BIALAKOWSKI; LUSNICH, 1995; SANDIA, s.f.), "poner orden" al desorden urbano que había sido creado por las propias autoridades y los actores privados, con la salvedad de que las autoridades culpaban a las administraciones anteriores.

\section{EL APEGO A LA MATRIA DEL MIEDO}

Resaltar los efectos positivos de la periferia o de ciertos personajes como grandes ejemplos resulta un 'motor emocional' positivo para los habitantes y busca disminuir el miedo producido por el desastre. El opuesto al apego es el estigma territorial (GOFFMAN, 2006). Bajo diferentes formas, parece que vivir en la periferia se asocia regularmente con los pobres y con la concentración de la violencia (TORTOSA, 2011). Cuando un territorio ha sido estigmatizado, las personas no se identifican con él, no se sienten ligadas con los otros y se crea una distancia afectiva entre ellos "quieren evitar el estigma y se lo pasan unos a otros" (WACQUANT, 2006). Se trata de una ambivalencia no negativa: la idea "salir" (de la condición de pobreza) es una metáfora que da esperanza, pero "salir" aquí significa también aceptar "quedarse", aceptar esa condición y "luchar unidos". Véanse algunos ejemplos.

a) Maribel Dominguez, conocida como Marigol, futbolista internacional de la liga femenil. Su figura se promueve como originaria de un "poblado miserable de la periferia de México, con chabolas (sic) y calles de tierra, donde la luz eléctrica llegó hace apenas unos años" (El País, 1 de mayo de 2005). $\mathrm{Al}$ respecto menciona: Cuando fue entrevistada afirmaba "creo que he salido de lo más bajo, y Chalco no es aún una población muy bien establecida", promueve una idea de comunidad "estamos luchando", que surge de una condición extrema "La colonia donde vivo ni siquiera tiene las calles pavimentadas" que un tipo de población activa, "También es un modo de lucha, ¿no? Sufres mucho en lo que haces y en cómo vives, y al mismo tiempo quieres luchar y sobresalir al máximo" (Entrevista a Marigol en el periódico El País, 1 de mayo de 2005).

b) Los Niños cantores de Chalco, habitantes del valle olvidado por Dios, como se citó en los medios de entonces, era una "agrupación coral" formada en 1990 con el objetivo de interpretar piezas de ópera durante la visita del Papa Juan Pablo II a México. Una vez cumplido su cometido, la agrupación no se disolvió, pero para sus autores es una "utopía social realizable" (La Jornada, 29 de junio de 2004). 
c) El Papa Viajero en Valle de Chalco, en la segunda ocasión que visitó México, en 1990, Juan Pablo II estuvo en Valle de Chalco. A partir de entonces se resaltaron en el municipio las historias de esfuerzo personal frente a la marginalidad, y las organizaciones de apoyo comunitario cobraron fuerza. En ocasión de su visita, el gobierno había preparado un escenario de "logros" ${ }^{7}$ : instaló electricidad, agua potable, drenaje y pavimentado de calles, creando la percepción de una fuerte cohesión social. Algunos de sus habitantes aseguraban que Chalco fue "creado" a partir de la visita del jerarca religioso:

¿Por qué el Papa decidió visitar Chalco? Me parece que es una interrogante permanente. Pero la versión que parece ser la más verídica es que su Santidad pidió que lo llevaran a una de las comunidades más marginadas y tal parece que pensaron en la orilla de San Miguel, la cual en ese entonces no tenía luz, ni agua, tampoco drenaje y se encontraba, todavía en 1990, en un gran olvido. (Entrevista a habitante de Chalco aparecida en el periódico El Universal, $1^{\circ}$ de mayo 2011).

¿Por qué el gobierno tendría tanto interés por regularizar la tierra? ¿Por qué se atendió con tanto énfasis a Chalco? Hay algún interés detrás o en su caso usan ejemplos de figuras importantes para convencer a la gente, (in)movilizar mediante el uso de la reconciliación para hacer ver que el quedarse vale la pena.

Esa comunidad creada por el uso político que la autoridad hizo de ellos, parece conmoverse con el advenimiento de los desastres sucesivos. En el transcurso de los años siguientes, esa legitimidad alcanzada fue nuevamente cuestionada debido a los desastres recurrentes en forma de inundaciones por aguas negras.

\footnotetext{
${ }^{7}$ Según CNN Juan Pablo II "no solamente fue un actor que representaba la religión, sino que podemos también categorizarlo como un actor político, un activista de su propia religión", Dra. Iliana Rodríguez Santibáñez, Directora del Departamento de Estudios Jurídicos y Sociales, Tecnológico de Monterrey, Campus Ciudad de México (citado en CNN, 21 de abril de 2014).
}

\section{LAS ESTRUCTURA EMOCIONAL DEL DESASTRE}

Chalco es una construcción emocional en el riesgo (SWYNGEDOUW, 2011), donde sus habitantes viven en el temor al otro (al pobre) ya que sus prácticas irrumpen en la naturalidad del tejido social establecido ${ }^{8}$. $\mathrm{Al}$ mismo tiempo, en Chalco la 'naturalidad' del status quo urbano discrimina todo aquello que lo aleja del modelo 'civilizado' y de progreso: los indígenas, los indigentes, los pobres, etc. En este discurso, precisamente, ocurre la construcción social del miedo hacia aquellos 'no urbanos' o que' somete' a aquellos que necesitan 'adaptarse'. Chalco es una fuente sociológica del miedo.

Aquí el miedo lo entendemos como una emoción negativa que incide en la construcción intersubjetiva del espacio urbano. El miedo posibilita un tipo de 'urbanismo periférico' o de 'exclusión estratégica', como se le llama en algunos trabajos (DE ALBA; CRUZ, 2013), un espacio insuficiente en su integración, un escenario de 'de riesgo' cotidiano.

Es un miedo que en lugar de facilitar la interacción entre aquéllos que se sienten amenazados y los que se sienten ajenos, en lugar de eso, los fragmenta. Este miedo 'encierra' y 'separa' a unos de otros dentro de la memoria individual y social. En ese sentido, el municipio de Valle de Chalco es producto de ese temor que los hace reconocerse (o no) como los otros, los extraños, los olvidados de la ciudad.

El habitus urbano del miedo es el espacio de las percepciones que se fue generando a partir tanto de percepciones de desconfianza e inseguridad, como de continuidades y logros, creándose 'territorios emocionales', nuevas intersubjetividades, y por tanto, la acumulación de espacios de vulnerabilidad emocional ${ }^{9}$.

\footnotetext{
${ }_{8}^{8}$ Tal como lo sugiere Joseba Juaristi, "la ciudad postmoderna ofrece diferentes incertidumbres y motivos de miedo. No sólo el miedo al delito, a la violencia física, o al terrorismo, sino también el miedo a la pérdida de las coordenadas de identidad personal, la pérdida del carácter de los espacios públicos, el miedo a los extraños y a los diferentes, a los paisajes anodinos y carentes de sentido" (JUARISTI, 2005, p. 272).

9 "La vulnerabilidad es una construcción social que depende de los siguientes factores: a) económicos: escasez de medios; b) políticos: carencia de normas eficaces; c) ecológicos: medio ambiente con grandes
} 
Para los habitantes de Chalco llegar, habitar el nuevo territorio, es una percepción de una vida emocional en el riesgo ${ }^{10}$.

Aquí las inundaciones son eventos urbanos socioambientales (SWYNGEDOUW, 2006), porque refieren un carácter emocional, porque son provocadas por una serie de intervenciones sobre un espacio (real o simbólico), por parte de actores estatales y no estatales.

Según Victoria E. Valencia (2007), los imaginarios del miedo tienen "una conexión a situaciones ambientales concretas, la ciudad actual representa el miedo, la carencia, la frustración". Para la autora, el miedo ecosistémico es producto de la transformación antrópica sobre la naturaleza, por el afán de convertir todo espacio en ciudad, trae consigo destrucción y degradación ambiental, asimismo eventos de mayor magnitud como sismos, temblores, terremotos, inundaciones, lluvias y la contaminación del aire" (VALENCIA, 2007, p. 187).

Ello produce un mélange emocional: se desarrollan en la población los sentimientos de pérdida de sus bienes o de su patrimonio familiar; de frustración por la inundación repetida de aguas negras; la desesperanza por la percepción de imposibilidad de cambiar esa condición; de impotencia por la manipulación que observan en las autoridades en el manejo de las contingencias.

\subsection{La impotencia y la pérdida como acción política}

¿Cómo puede identificarse rasgos de 'acción política' en los comportamientos emocionales de los afectados?

En la inundación del 15 de febrero de 2010 vecinos de la colonia San Isidro, Valle de Chalco Solidaridad, bloquearon la autopista México-Puebla - una importante vialidad que funciona como salida de la capital del

amenazas; d) culturales: prácticas de reproducción social que afectan la seguridad; e) organizativas: falta de conciencia y capacidad de organización para fines comunes: e) institucionales: incapacidad gubernamental para tomar decisiones e implementarlas" (PARRA, 2005 citado en PUEC-UNAM, 2008, p. 3).

${ }^{10}$ De tal manera que llegar implica no sólo estar en un nuevo lugar que ha de ser despojado de su carácter agreste para "civilizarse" o "urbanizarse", sino también nombrar, dar existencia al entorno nominando rasgos en el paisaje y el mundo social próximo (DÍAZ, 2011, p. 149). país hacia el sureste, además de dar acceso a miles de trabajadores de la ciudad ${ }^{11}-$, para protestar por la falta de apoyo del gobierno federal y estatal. Sin embargo, el bloqueo duró unas horas y después llegaron patrullas de la Agencia de Seguridad Estatal (ASE), para desalojarlos violentamente con golpes ( $\mathrm{La}$ jornada, 16 de febrero del 2010).

La impotencia habita los discursos emocionales de los afectados. En las tres inundaciones de aguas negras en el Valle de Chalco se evidenciaron altos niveles de vulnerabilidad en los habitantes. Las pérdidas materiales parecían inevitables en un lugar que es imposible mantenerse a salvo debido a su cercanía con el canal de La Compañía. Por ello, en cada temporada de lluvias, la incertidumbre de los pobladores se ha expresado en la angustia de perderlo todo y de otra vez "quedarse en la calle." La angustia trastoca el medio ambiente y lo vuelve una 'urbe emocional':

\section{- "¿Y en las noches cuál es la sensa- ción en estas zonas? -Respondió en una entrevista una afectada: \\ - “Yo no puedo dormir nada más de
escuchar agua" (El Universal, 12 de
febrero de 2010).}

Si la impotencia puede generar protestas, la pérdida genera una comunidad hídrica imaginada, cohesionada en la desesperanza, en la imposibilidad de cambio, en la pérdida. ${ }^{12}$

Durante las inundaciones, las azoteas se convirtieron en los lugares en los cuales la gente podía guarecerse del cauce de las aguas negras. Se trataba de una "lugar" para el encuentro emocional: desde la 1:30 de la ma-

\footnotetext{
${ }^{11}$ En un estudio, realizado por la DGST-SCT en el año 2007, sobre la autopista México-Puebla se estableció que circulan 26,396 vehículos en promedio diario anual. En dicho estudio de observa que la carretera México-Puebla se encuentra dentro de las primeras cinco carreteras más concurridas del país, tomando en cuenta 861 carreteras del país (RODRÍGUEZ, 2012).

12 “En términos simbólicos, en la configuración de las $\mathrm{CHI}$ pueden presentarse dos rasgos principales, como articuladoras de acción política: a) Hay una articulación compleja de su identidad (negada o asimilada) a partir de sus significaciones y temporalidades que la comunidad da al recurso natural (natural o urbanizado); b) Hay una articulación de emociones como la cohesión y la fraternidad a partir de la relación socio espacial que la comunidad al recurso natural" (DE ALBA; CASTILLO, 2014, p. 5)
} 
drugada de ese día, ancianos, mujeres y niños permanecieron allí postrados, esperando o dándose la ayuda que el gobierno, los policías o el ejército tardarían en proporcionarles ( $\mathrm{La}$ Jornada, 18 de abril de 2011). Otro vecino lo ilustra claramente:

- Tengo mucho coraje, apenas estábamos levantando el negocio que perdimos el 5 de febrero de 2010 [la anterior inundación, ndlr], y mire, otra vez nos quedamos en la calle ( $\mathrm{La}$ Jornada, 18 de abril de 2011).

La impotencia no es una emoción que se analice aquí 'psicológicamente', sino en sus connotaciones políticas. En el individuo la emoción de la impotencia cohesiona, articula en la pérdida, une en la reconstrucción de su patrimonio, aún con la falta de recursos económicos y a la poca o nula cobertura de las indemnizaciones por parte de los distintos gobiernos.

Afectada: Vino el señor Peña Nieto pero no deja hablar, los que viene con el no dejan que uno se acerque, solo yo le diría que pues que ya pongan una solución porque realmente él no está viviendo esto, él duerme calientito [...] (NoticiasTVCn, 19 de abril del 2011)

De allí que la aparente 'inacción' frente al desastre sea constitutiva de comunidad, y por lo tanto, el 'desborde' de esas emociones sea generadora de acción política. El miedo al desastre y la desesperanza, o la impotencia reflejan un cuestionamiento claro a la autoridad, y como tal, aunque no se traduzca en una acción directa, hace comunidad. $\mathrm{Al}$ respecto José, otro afectado, dice:

Después de la inundación hubo por ahí unos cheques, un apoyo de diez mil pesos por hogar, con la finalidad de medio mitigar el daño, que realmente diez mil era muy poco, mínimo de lo que perdimos nosotros fue un refrigerador que valía ocho mil pesos, hay gente que perdió más cosas. También dieron vales, que sólo podían ser canjeados en algunas tiendas y por productos que algunos no requeríamos, por ejemplo frituras y otras cosas de despensa caducadas etc. [...] había un pacto, un control donde sólo salieron beneficiados algunos, aunque la gente llegó a perder muchas cosas. La ayuda aparte llegó como a los dos o tres meses después, porque antes de eso hicieron las autoridades un inventario, pero sólo para despistar y controlarnos. Para darte la ayuda tenías que certificar que la casa era tuya, tenías que enseñar las escrituras, también debías presentar fotografías o videos. Los que vivimos de este lado, donde aún no se encuentra entubado el canal, seguimos con el temor de que se desborde y de perderlo todo otra vez. (Entrevista de tipo exploratoria, 10 de febrero de 2012, Valle de Chalco).

En la población afectada se percibe la fuerza emocional producida por la vivencia del desastre, en la medida que identifican a los 'culpables', a los responsables de su pérdida: las autoridades.

La gran inundación que pasamos en 2010, no sé si su causa sólo fueron las lluvias, más bien es la negligencia por parte de las autoridades. Se rumoraba que se pudieron abrir unas compuertas del Canal, que ya estaba en funcionamiento, pero se negó la autorización, dicen que esto hizo que el Canal se saturara y se reventara, que si hubieran abierto las compuertas el agua habría encontrado otro lugar hacia donde irse. Creo que los responsables directamente de las inundaciones y de lo que nos pasa, es el gobierno del estado, también podíamos decir que las autoridades locales, pero siempre se deslindan diciendo que es cosa 'de más arriba', de los otros gobiernos; dicen que como es un canal que atraviesa varios municipios, entonces no pueden tomar decisiones por sí mismos. (Entrevista de tipo exploratoria, 10 de febrero de 2012, Valle de Chalco).

El miedo después del desastre expresa la incapacidad social de ambas partes (autoridades y afectados) para generar acciones conjuntas en la prevención de las inundaciones.

La acción política es la supervivencia Los afectados esperan que las autoridades cumplan con la indemnización de las pérdidas; o visto miedo articulado, los afectados implementan acciones para salvaguardar sus pertenencias, como construir segundos pisos a sus viviendas, bardas de tabique en 
las entradas de sus casas o negocios, entre otras cosas.

La pérdida está también en quedarse, en no tener otro remedio. El argumento de que a los habitantes de este lugar no les ha importado vivir en una zona de riesgo, como hemos visto es poco creíble, ¿Es que la población no tiene conciencia del riesgo al que se enfrenta? Esta es una pregunta al pensar en Chalco 'desde afuera'.

Puede suponerse que más que falta de conciencia, el desastre siempre provoca incertidumbre, aunque también se desarrolla una 'cotidianidad' a la precariedad del terreno, por la necesidad de contar con un hogar propio. Los medios de comunicación han sido prolíficos en ejemplos al respecto.

- Reportero: Señora, ¿Cómo está? ¿Cómo la paso?

- Señora: No pues bastante mal, la verdad estamos sufriendo mucho con este problema del agua, cada vez que pasa esto, cada año tenemos el mismo problema, ya necesitamos que las autoridades nos ayuden... $\mathrm{mmm}$... no sé qué decir, la verdad ya no sé qué decir porque hemos pedido el apoyo al presidente, a la comunidad de Chalco, la verdad lo que nosotros necesitamos es que nos ayuden con material, ya no con ropa y con víveres sino con material para la construcción [...]

- Reportero: cuánto tiempo se tarda en sacar el agua y en recuperar la normalidad para vivir aquí?

- Señora: No pues ya definitivamente estamos viviendo sobre el agua, cada año es lo mismo, ya nos estamos acostumbrando con vivir con el agua, miren ahorita, nosotros sacamos el agua y todavía hay bastante, se filtra totalmente [...]

- Reportero: Y en cuanto tiempo saca el agua?

- Señora: Más o menos en 4 o 5 hrs.

- Presentador: [...] la historia de cada año, sí, pero varias veces cada año

- Presentadora: La señora dice que se tardan $5 \mathrm{hrs}$. en quitar el agua, pero se tardan muchos días en quitar la humedad de la casa, en poder recuperar los muebles y lo más trágico de todo esto es lo que las personas normales podrían considerar una tragedia al ver la inundación absoluta de su casa, ellos ya se están acostumbrando [...] (Entrevista a mujer afectada de la inundación de 2010 en la colonia Isidro Favela, oriente 15. Hechos TV, 2010).

Se trata de una vida cotidiana impregnada de desesperanza como una emoción construida políticamente en el olvido, en la recurrencia del desastre.

- Reportera: Hace ya 4 días de la inundación en el Valle de Chalco y lo único que queda entre los afectados es el miedo y la incertidumbre

- Niña: Pienso que nos vamos a inundar y nos vamos a ahogar.

- Reportera: Hasta hoy el Valle de Chalco solo ha vivido la primera lluvia de la temporada, sus habitantes lo saben pero también saben que no tienen otra opción...

- Afectada: No me queda de otra más que estar aquí. [...]

- Afectada 2: Ya no queda el llanto, ya lloramos mucho en otras inundaciones pasadas, ya nos conmovimos demasiado y ya no hay tiempo para el llanto.

- Reportera: Admira uno la entereza de todos ustedes que se cae todo esto y se vuelven a levantar y se vuelven a levantar

- Afectada 3: Mientras tengamos vida que el Señor nos guarde vamos a estar aquí $[\ldots]$

- Reportera: ¿Hace cuánto que vive aquí?

- Afectada 3: Yo tengo 22 años aquí en el Valle de Chalco

- Reportera: ¿Y no le dan ganas de irse de aquí?

- Afectada 3: Aaay!, ya nadie quiere ni comprar este terreno $[\ldots]$ 
- Afectada 2: Y aquí pues nada está escrito, porque puede volver a ocurrir desgraciadamente (Entrevista grupal a afectados en la inundación de 2011, NoticiasTVCn, 19 de abril del 2011).

La existencia de tiempos y funciones del miedo que crean una comunidad hídrica imaginada: miedos que se repiten y provocan escenarios políticos dominados por el desastre, vida urbana en la que le emocion es articuladora de la acción política y futuros sociales, individuales y colectivos, de incertidumbre.

\section{CONCLUSIONES}

¿Cómo se estructura el miedo líquido en escenarios de desastre? Aquí se planteado que para 'estructurar' un estudio sobre las emociones en el desastre requiere considerar varios aspectos relevantes.

Primero, una constatación: la acción política es tratada en los estudios tradicionales de sociología o ciencia política como 'fuera' de las emociones colectivas, lo que vacía de sentido político a la vida cotidiana.

Segundo, la acción política cuando es analizada como un proceso 'consciente' del comportamiento social ha excluido a las emociones como articuladoras de la misma. Particularmente, cuando se trata de emociones negativas que 'paralizan' al individuo, como en los casos del miedo, la desesperanza, el sentimiento de pérdida, entre muchos otros. Aquí se demostró que dichas emociones son potenciadoras de la acción política directa o indirecta, aunque hay que insistir, no bajo los criterios del análisis social tradicional.

En el caso del miedo, éste es parte de una crisis de legitimidades que se advierte en la percepción social, por ejemplo, sobre las acciones de carácter paliativo que desarrollan las autoridades en escenario de desastre.

En el caso de las inundaciones de Chalco, los grupos sociales perciben que la intervención institucional no es eficaz para evitar la ocurrencia repetida del desastre, sino que las autoridades buscan mantener, o evitar que su legitimidad no sea cuestionada por dichos grupos.

En dicho sentido, el miedo es una herramienta política que sirve para legitimar políticas de control y regulación por parte de autoridades gubernamentales, porque "cuanto mayor es la preocupación por la inseguridad, mayor es la disposición de los ciudadanos a someterse a mecanismos de dominio" (LÓPEZ, 2011, p. 75). Además de las instituciones de gobierno, los medios de comunicación usan el miedo como discurso político para ocultar corrupción, o para exponer 'destinos sociales' (la pobreza es inevitable), o usando discursos moralizantes para culpabilizar a aquéllos que 'no hacen nada' por salir de su situación de riesgo. En general se prolifera el miedo, se asusta con la amenaza del desastre para 'ajustar', 'recuperar' legitimidades del sistema político en cuestión.

Tercero, en los discursos en torno al desastre se hacen tipologías sociológicas del miedo. Se asocia comúnmente esta emoción negativa con problemáticas socioeconómicas, aunque ligadas a la 'indiferencia' de los propios afectados, o al olvido que sufre esa población por parte de funcionarios; o la recurrencia a discursos relativos a la pérdida del hogar usados como una emoción política' (búsqueda de simpatías en tiempos de crisis); o se usan 'figuras importantes' para (des)movilizar (el Papa, una deportista), para recuperar la idea que el esfuerzo y el sacrificio dan frutos. Entonces se propaga un discurso de la reconciliación para hacer sentir que el quedarse vale la pena, que es algo que el gobierno les reconoce; o para identificar genealogías de futuros sin esperanza (sinónimo religioso de individuos con futuros vedados), entre muchas otras.

Cuarto, las razones de quedarse tienen que ver con proceso emocional de la urbanización. Así, el patrimonio se significa como apego a la tierra, es la representación de décadas de esfuerzo colectivo (familiar), por eso el miedo a la pérdida adquiere tanta significación. Para una población en la pobreza, el irse genera el miedo 'a que se vuelva peor', porque no se sabe qué viene después. De otra manera, en la población existe una autopercepción que define políticamente a la inmovilidad: "no tenemos donde ir", "nos quedamos aquí" son frases de quienes aparentemente no tienen ningún poder, pero que se sirven de él para resignificar sea su condición de olvidados, sea para darse esperanza de una movilidad inocua, "aunque sea tres cuadras adelante". La emoción política de la inmovilidad les dice 
que deben dejar de buscar porque la ciudad no da opciones y el vivir "fuera" de la ciudad no es una opción para ellos.

Quinto, el miedo tiene efectos tanto concatenadores como desencadenadores, particularmente con la generalización de paliativos -que hacen que los afectados "recuperen el refrigerador" al menos-. Aquí encontramos los rasgos de una geografía emocional del miedo como articuladora de la comunidad hídrica. El espacio define las características del miedo como "efecto" del desastre; mientras que la temporalidad subraya la forma como el miedo articula a la comunidad.

Los efectos desencadenadores del miedo puede encontrarse, cuando los medios de comunicación dicen: "lo que las personas normales podrían considerar una tragedia al ver la inundación absoluta de su casa, ellos ya se están acostumbrando". Los medios, como dadores de legitimidad, "evalúan" de manera positiva la desesperanza. El miedo cuando se enfrenta con esfuerzo desencadena ejemplos que articulan de nuevo a la comunidad. Esa utilización positiva de los afectados por el desastre conlleva a la negación de la "huida", porque "salir corriendo" no es digno. El miedo desencadena la lucha por una dignidad en el sufrimiento.

Es decir, en este discurso positivista del sufrimiento, la acción (o la inmovilidad) es siempre el recurso de la dignidad en la pobreza. La población de Chalco tiene condiciones culturales que los habitúa a pelear para resolver sus problemas. El miedo es parte de la vida cotidiana, pero en el caso del miedo por el desastre recurrente hay una concatenación de desesperanza y extrañamiento, como una resignación y al mismo tiempo como un apego a la tierra.

Entonces, para responder a la pregunta ¿el miedo en el desastre es motor de acción política? En este artículo hemos tratado de destacar la significación de algunas características del miedo frente a situaciones del desastre, específicamente el miedo líquido, utilizando el concepto de Bauman (2006) como las múltiples formas de transformar el riesgo en iniciativa en la vida urbana.

Entonces puede sugerirse que el miedo como emoción política no genera una acción política tradicional, es decir ligado a los partidos, subordinado a las instituciones o como parte del juego democrático tradicional. Más bien, se refiere a la imprevisibilidad de las emociones individuales y colectivas alrededor del desastre.

El "deben irse" es la voz recurrente de los empleados de gobierno, funcionarios y políticos (argumentando que no es seguro el lugar, el tiempo en el que el desastre transcurre, después de que ellos mismos dieron tierras para habitar) y, del otro lado, la voz silenciosa "no queremos irnos porque no tenemos a donde irnos". El miedo es una emoción política cuando a los habitantes de Chalco parece "no haber salida" a las inundaciones recurrentes porque, de un lado, los individuos no quieren irse porque tienen un patrimonio, tienen estructura emocional de apego al suelo; y por otro lado, porque hay una desesperanza por la percepción de la incapacidad del Estado en la búsqueda de alternativas.

Quinto, los discursos comunes al desastre que facilitan, propagan, inhiben, y resignifican al miedo están articulados por la culpa. Las intervenciones que se hicieron notar en este artículo de parte de las autoridades en su diferente nivel federal ocurren una serie de culpabilizaciones frente al desastre en dos sentidos: uno, culpar a las autoridades de más bajo nivel; culpar a los habitantes que no se quieren ir o culpar a su inconsciencia porque sabían que esa zona era vulnerable; dos, evitar culparse demasiado "porque no es bueno" (moral cristiana de la resignación); evitar culparse porque puede "dar alas" a la iniciativa social contestataria, como aquellos que demandan indemnización por los desastres que vivieron.

Recapitulando, la construcción de la noción del miedo cotidiano con emoción política en el desastre constituye comunidad hídrica imaginada (DE ALBA; SALAZAR; MARTIN, 2015) desencadenadora y concatenadora. El miedo se vive en la desesperanza y en la pérdida: "se ha perdido todo, pero nosotros no nos hemos perdido", "se ha perdido todo, pero aquí seguimos", "se ha perdido todo de nuevo pero tenemos que seguir luchando".

En el caso de las inundaciones de Chalco, la acción política de la comunidad hídrica imaginada se encuentra en las voces que están pidiendo que la ayuda sea suficiente; que la recuperación de sus bienes esté articulada por uno gobierno legítimo (que cumpla sus promesas). En términos sociológicos, la lectura 
de la intervención institucional (gobierno, medios, otros) supone que esta comunidad construida es manejada a partir del desastre.

La comunidad hídrica imaginada se centra en esa condición de todos tenemos miedo, que es lo que hasta ahora ha mantenido, sostenido, reunido a la misma.

\section{REFERENCIAS}

BAUMAN, Z. Miedo líquido. España: Paídos, 2006.

BIALAKOWSKI, A.; LUSNICH, C. Procesos de formalización de la informalidad. Flexibilidad y condiciones de trabajo precarias, 1995.

BLÁSQUEZ Martínez, L. La Ciudad de México y sus fronteras ecológicas: Reformulaciones espaciales, representativas y de poder. Nueva Antropología, p. 155-177, 2012. En línea: <http://www.redalyc.org/articulo. oa?id=15929703008>.

DE ALBA, Felipe; Castillo, Oscar. "Después Del Desastre... Viene La Informalidad" Una Reflexión Sobre Las Inundaciones En La Metrópolis De México. Revista de Direito da Cidade, 6 (1), p. 141-167, 2014.

DE ALBA, Felipe; CRUZ, Carlos. Potencialidades conflictivas del stress hídrico: ¿Las resistencias sociales desbordan territorios en México? Reflexión Política, 15 (30), p. 24-37, 2013.

DE ALBA, Felipe; SALAZAR, Yessenia; MARTIN, Juana. Comunidades Hídricas Imaginadas en la metrópolis de México, nuevas percepciones del conflicto hídrico. 2015. En prensa.

DÍAZ, M. A. Del espacio al lugar: un análisis de la consolidación urbana local desde la perspectiva narrativa. Alteridades, 21(4), p. 145-160, 2011. En línea: <http:/ / www.scielo.org.mx/scielo.php?pid=S0188$-70172011000100014 \&$ script $=$ sci_arttext $>$.

FIGUEROA Encino, Alicia. Estudio geomorfológico general y aplicada a peligros en la zona del lago de Chalco, Estado de México. 2007. Tesis (Licenciatura en Geografía) - Universidad Nacional Autónoma de México, Facultad de Filosofía y Letras, Colegio de Geografía, México.

GOFFMAN, Erwin. La identidad deteriorada. Buenos Aires: Amorrortu, 2006. 173p.

GÓMEZ García, Celia. Riesgo por inundaciones en la zona metropolitana de la Ciudad de México. 2004Tesina (Licenciatura en Geografía) - Universidad Nacional Autónoma de México, Facultad de Filosofía y Letras, Colegio de Geografía, México.

HEWITT, K. Daños ocultos y riesgos encubiertos: haciendo visible el espacio social de los desastres. En: MANSILLA, E. (Coord.). Desastres Modelo para Armar. Colección de Piezas de un Rompecabezas Social. Costa Rica: Red de Estudios Sociales en Prevención de Desastres en América Latina, 1996.

JUARISTI, Joseba. El aire de la ciudad postmoderna: Identidad, espacio público, cultura y miedo. En: GUTIÉRREZ, Obdúlia (Coord.). La ciudad y el miedo. VII Coloquio de Geografía Urbana, Universitat de Girona, (Diversitas, 52) 269-287, 2005.
LÓPEZ Levi, L. Fortificaciones habitacionales en México: De la violencia dominante a la violencia dominadora. Argumentos, México, DF, 24(66), 61-81, 2011.

MAGALLANES, G.; BAHENA, A.; RAMOS, A.; FENOGLIO, F. La rebeldía de Valle de Chalco, La lucha contra las aguas negras y el mal gobierno. Revista Rebeldía, 70: 18-29, 2010. En línea: <http://revistarebeldia.org/ revistas/numero70/06chalco.pdf>.

MAZARY M.; PLATAS, F. Cuatro Grandes en el Salvamento de la Ciudad de México ante Inundaciones. México: El Colegio Nacional, 1999.

ORTIZ de Zárate, Roberto. Biografias Líderes Políticos. CIDOB Barcelona Centre for International Affaires Carlos Salinas de Gortari, 2007. En línea: <http:/ / www. cidob.org/ $>$.

ORTIZ, D.-C.; ORTEGA, M. A. Origen y evolución de un nuevo lago en la planicie de Chalco: implicaciones de peligro por subsidencia e inundación de áreas urbanas en Valle de Chalco (Estado de México) y Tláhuac (Distrito Federal). Investigaciones geográficas, (64), p. 2642, 2007. En línea: <http://www.scielo.org.mx/scielo. php?pid=S0188-46112007000300003\&script $=$ sci_arttext $>$. PUEC-UNAM. Pobreza, agua y cambio climático en la ciudad de México. Informe Final. Coordinación de Humanidades, UNAM, PUEC, GDF, Centro Virtual de Cambio Climático de la Ciudad de México (CVCCCM). México, p. 110, 2008. Disponible en: <http://www.conagua. gob.mx/CONAGUA07/Contenido/Documentos/ AyCCMex2007-2012.pdf>.

SANDIA, L. A. Informalidad y pobreza: Impactos en la Gobernabilidad de las Ciudades. (s.f.). En línea: <http:/ / webdelprofesor.ula.ve/arquitectura/rojomaria/P/ Luis\%20Sandia.pdf>.

SEMARNAT. Informe de la Situación del Medio Ambiente en México 2012.

SWYNGEDOUW, E. ¡La naturaleza no existe! La sostenibilidad como síntoma de una planificación despolitizada. En Urban, (01), p. 41-66, 2011.

TORTOSA, J. M. Mal desarrollo y mal vivir. Pobreza y violencia a escala mundial. Polis, Revista de la Universidad Bolivariana, 10(28), p. 595-599, 2011.

TOSCANA, Alejandra. Actores sociales en la gestión social del riesgo de desastre en Valle de Chalco Solidaridad, Estado de México. Espacialidades, 4 (1), p. 137-169, 2014. En línea: <http:/ /espacialidades.cua.uam.mx>.

VALENCIA, Victoria. Imaginarios del miedo en el contexto urbano de Manizales. Gestión, 10(2), 2007. En línea: <http:/ / www.revistas.unal.edu.co/index.php/ gestion/article/viewFile/1421/2045>.

WACQUANT, L. Castigar a los parias urbanos. Antípoda. Revista de Antropología y Arqueología, (2), p. 59-66, 2006. En línea: <http://www.redalyc.org/ pdf/814/81400205.pdf $>$.

WILCHES, G. La vulnerabilidad global. En: MASKREY, A. (Coord.). Los desastres no son naturales. Bogotá: La Red, 1993.

ZILBERT, Linda. Gestión local del riesgo. Material de apoyo para la capacitación. Desarrollando los contenidos. SE-NPMAD, PNUD, COSUDE, TGL/INIFOM. 2001. 


\section{PERIÓDICOS EN LÍNEA}

CNN (21 de abril de 2014) 1992: el año en que Juan Pablo II y Carlos Salinas 'hicieron clic'. Mauricio Torres.

El País (1 de mayo de 2005) Maribel es Marigol. Jordi Soler.

El Sol de Toluca (5 de agosto de 2012) Construyeron miles de casas sobre fallas geológicas, en Chalco. Juan Lázaro

El Universal (01 de mayo 2011). Juan Pablo II, el Papa que fundó un municipio en Edomex. Josué Huerta.

El Universal [Video-reportaje] (12 de febrero del 2010). La Inundación en Chalco. Mendoza, Luis Manuel. Ciudadanos en Red.

Hechos TV [Video-reportaje] (2010). Familias de Chalco pierden todas sus pertenencias por inundación.

La Jornada (11 de Junio de 2000). Fenómenos 'naturales'o corrupción y negligencia. Un sexenio de tragedias. A. Cano y Daniela Pastrana.

La Jornada (18 de abril de 2011). “Otra vez nos quedamos en la calle". René Ramón Alvarado y Javier Salinas.

La Jornada (19 de abril de 2011). Autoridades acuerdan medidas ante emergencias por lluvias. Alonso Urrutia.

La Jornada (2 de marzo de 2010). Inundaciones catastróficas en el Valle de México acabarán en 2012: Calderón. Claudia Herrera Beltrán.
La Jornada (2 de noviembre de 2011). Salinas, culpable de inundaciones: Luege. Alvarado, René Ramón.

La Jornada (28 de junio de 2011). Desgracias periódicas. Tragedias recurrentes, pese a obras millonarias. De la redacción.

La Jornada (29 de octubre de 2011). Recibe la CIDH queja de afectados por inundaciones en Netzahualcóyotl. René Ramón Alvarado.

La Jornada (5 de agosto de 2010). “El canal La Compañía, un basurero: Conagua". De la redacción

La Jornada (6 de febrero de 2010). Calderón recrimina a quienes 'no hicieron las obras a tiempo. Claudia Herrera Beltrán.

NoticiasTVCn [Video-reportaje] (19 de abril del 2011). Panorama desolador. Martha Reyes.

NoticiasTVCn [Video-reportaje] (19 de abril del 2011). Panorama desolador - Segunda parte. Martha Reyes.

Puño y letra (26 de agosto del 2011). La presidenta del Sistema Municipal DIF Luz Barrón Alcántara estuvo presente en la presentación de varios los libros.

Reforma, (31 de julio del 2014) "Hacen el Chalco fraude" Luis Fernando Lozano.

UNOTV (7 de septiembre del 2014). Inundaciones en el Valle de México se resolverán con nuevo aeropuerto". 